\title{
Idiopathic Arthritis Mutilans
}

RONALD R. BUTENDIECK JR, MD; ANDY ABRIL, MD, Division of Rheumatology, Mayo Clinic, 4500 San Pablo Road, Jacksonville, Florida, USA. Address correspondence to Dr. Abril; E-mail: abril.andy@mayo.edu. J Rheumatol 2013;40:1921-2; doi:10.3899/jrheum.130236

Arthritis mutilans is considered the most severe form of the 5 original clinical patterns of psoriatic arthritis described by Wright and Moll $^{1}$, but it also has been observed in rheumatoid arthritis, systemic lupus erythematosus, systemic sclerosis, juvenile idiopathic arthritis, multicentric reticulohistiocytosis, and cutaneous T cell lymphoma $2,3,4,5,6,7$. We describe a patient with more than 25 years of peripheral inflammatory joint symptoms and findings consistent with arthritis mutilans but without personal or family history suggestive of a specific underlying cause.

A 66-year-old white woman presented with recurrent flares of pain and swelling in her hands and toes associated with hours of disabling stiffness despite prescription nonsteroidal antiinflammatory drugs and narcotic agents. She had no previous treatment with disease-modifying antirheumatic drugs or corticosteroids. Physical examination noted 21 swollen and 21 tender joints, telescoping of multiple digits (Figure 1), foreshortening of her thumbs, and marked instability of her left metacarpophalangeal and right distal interphalangeal joints. Laboratory investigation reflected seronegativity. Inflammatory markers were within normal limits.

Hand radiographs showed severe erosive changes, pencil-in-cup findings, and absorption of the left thumb distal phalanx (Figures 2, 3, and 4). Magnetic resonance imaging of the hands demonstrated prominent enhancement of the affected joints. Wrists were spared. Sacroiliac joint radiographs were normal.

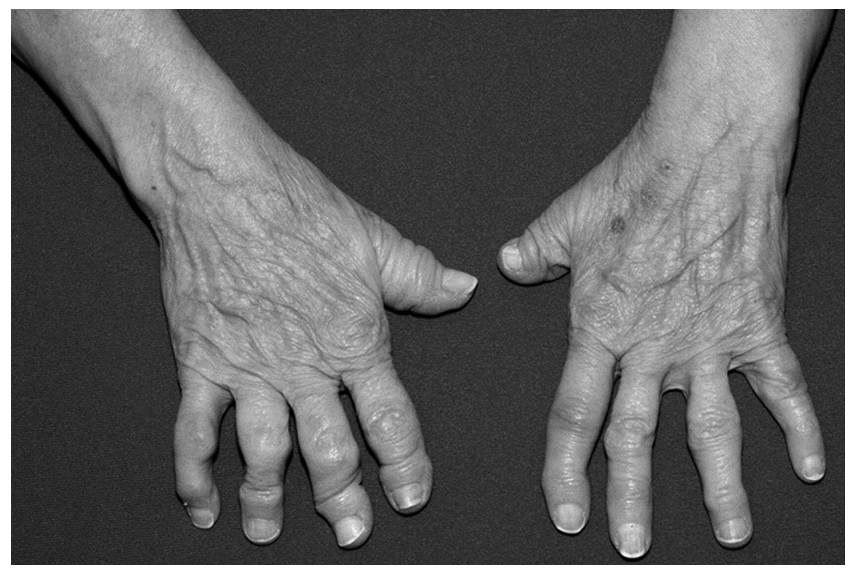

Figure 1. Bilateral view of the hands. Degenerative changes at multiple proximal interphalangeal and distal interphalangeal joints, with telescoping of several distal interphalangeal joints and signs of bilateral foreshortened thumbs.
Our patient had evidence of active, deforming, erosive polyarthritis with features of arthritis mutilans without clear evidence of an underlying cause. In light of her poor prognosis, therapy with a tumor necrosis factor inhibitor was started. Two months later, she reported substantial decrease in joint pain, swelling, and morning stiffness and had discontinued use of prescription pain medications.

\section{REFERENCES}

1. Wright V, Moll JMH. Psoriatic arthritis. In: Seronegative polyarthritis. Wright V, Moll JMH, editors. Amsterdam: North Holland Publishing; 1976:169-223.

2. Yoshida M, Belt EA, Kaarela K, Kauppi MJ, Shimamura T. Prevalence of mutilans-like hand deformities in patients with seropositive rheumatoid arthritis: a prospective 20-year study. Scand J Rheumatol 1999;28:38-40.

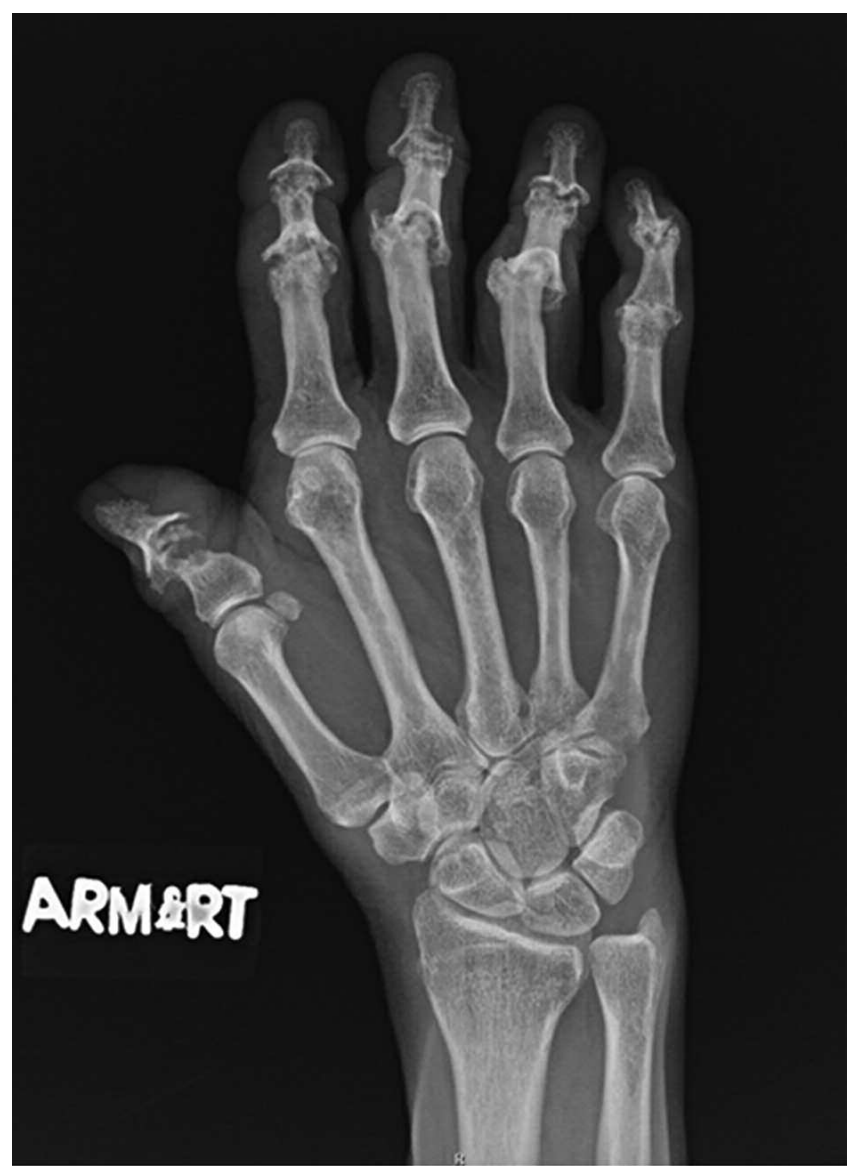

Figure 2. Posteroanterior radiographic view of the right hand. Markedly severe erosive changes are evident, with associated deformity involving all interphalangeal joints. Soft tissue swelling about multiple joints can be seen.

Personal non-commercial use only. The Journal of Rheumatology Copyright @ 2013. All rights reserved. 


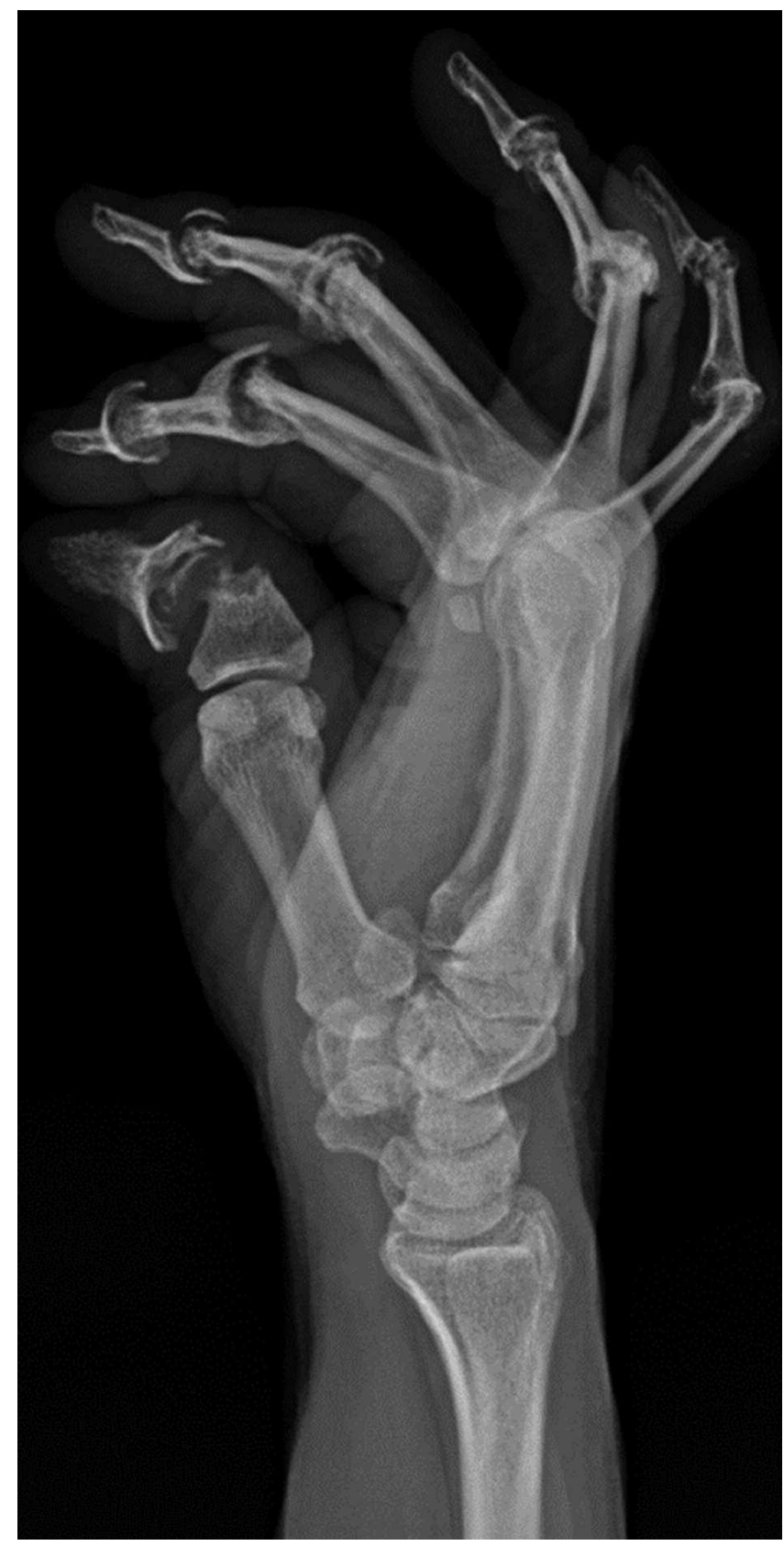

Figure 3. Lateral radiographic view of the right hand. Erosive changes with associated deformities are noted, involving all interphalangeal joints. Several deformities have a pencil-in-cup appearance.

3. Jakez-Ocampo J, Paulìn-Vera CM, Llorente L. Arthritis mutilans in a patient with systemic lupus erythematosus and rheumatoid arthritis. Joint Bone Spine 2010;77:374-5.

4. Sato T, Ozawa T, Kikuchi M, Nakano M, Gejyo F, Hanyu T, et al. A case of progressive systemic sclerosis associated with mutilans-type arthropathy and suspected Felty's syndrome [Japanese]. Ryumachi 1990;30:53-9.

5. Belt EA, Kaarela K, Kauppi MJ, Savolainen HA, Kautiainen HJ, Lehto MU. Assessment of mutilans-like hand deformities in chronic inflammatory joint diseases: a radiographic study of 52 patients. Ann Rheum Dis 1999;58:250-2.

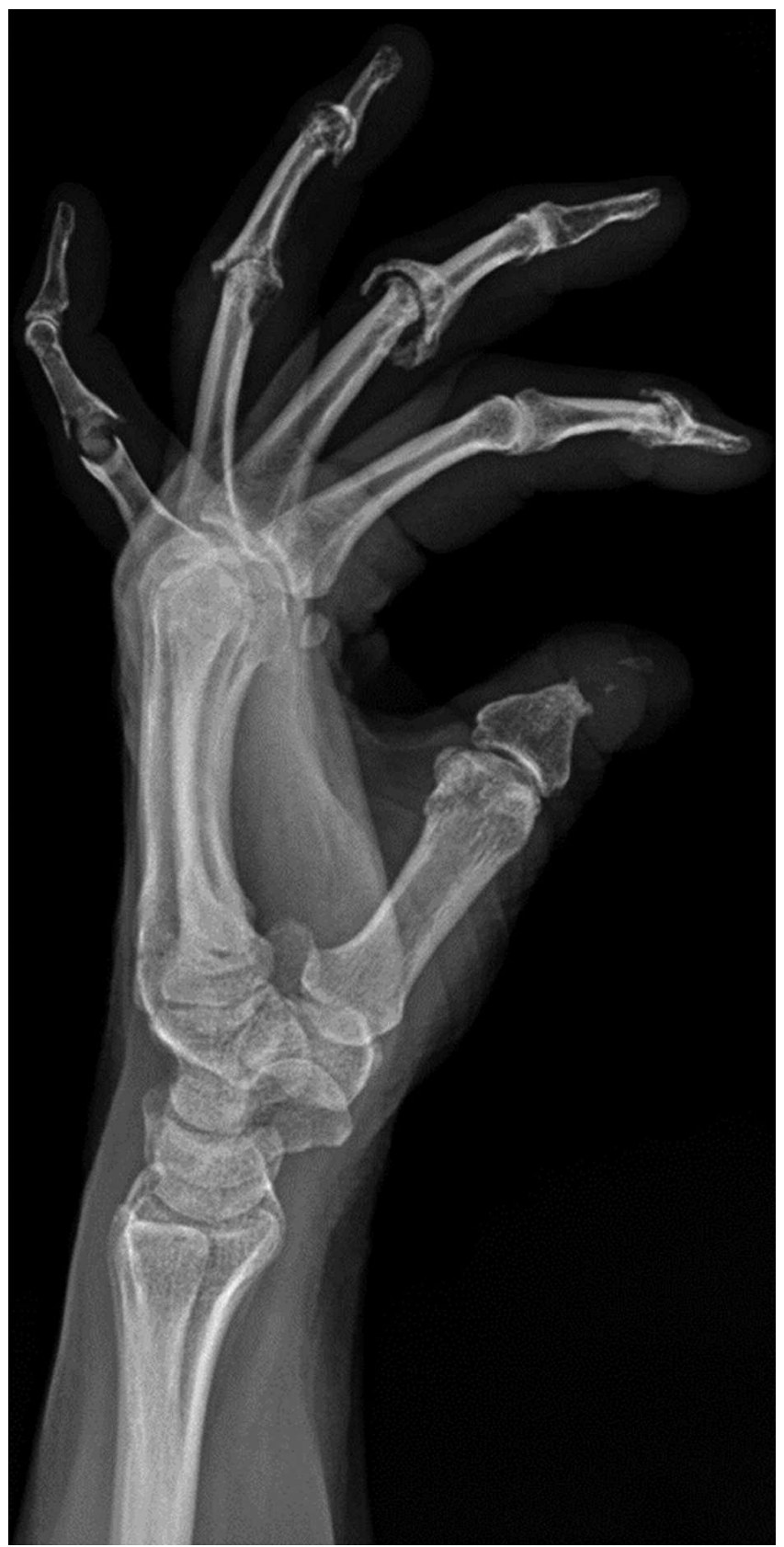

Figure 4. Lateral radiographic view of the left hand. Markedly severe erosive changes are evident. Associated deformity involves almost all interphalangeal joints, with relative sparing of the left third and fifth distal interphalangeal and second proximal interphalangeal joints. Radiograph also shows pencil-in-cup appearance of the third proximal interphalangeal joint and near-complete absorption of the left distal phalanx.

6. Saba R, Kwatra SG, Upadhyay B, Mirrakhimov AE, Khan FN. Multicentric reticulohistiocytosis presenting with papulonodular skin lesions and arthritis mutilans. Case Rep Rheumatol 2013;2013:201563.

7. Mathur A, Parhami N. Arthritis mutilans associated with cutaneous T cell lymphoma. J Rheumatol 1992;19:1489-90.

\section{Personal non-commercial use only. The Journal of Rheumatology Copyright $\odot$ 2013. All rights reserved.}

